\title{
Update on epidemiology of HCV in Italy: focus on the Calabria Region
}

\author{
Nadia Marascio ${ }^{1}$, Maria Carla Liberto', Giorgio Settimo Barreca', Emilia Zicca', Angela Quirino', \\ Angelo Giuseppe Lamberti ${ }^{1}$, Giovanna Bianco', Giovanni Matera', Lorenzo Surace², Giuseppina Berardelli , \\ Lidia Surace ${ }^{4}$, Vincenzo De Maria ${ }^{5}$, Francesca Giancotti ${ }^{5}$, Rosa Anna Leone ${ }^{6}$, Vilma Villella ${ }^{6}$, Salvatore Nisticò ${ }^{6}$, \\ Annelisa Borelli, Vincenzina Caruso ${ }^{6}$, Massimo Calderazzo ${ }^{3}$, Gianfranco Griffo ${ }^{3}$, Rosanna Masciari ${ }^{7}$, \\ Pasquale Minchella ${ }^{7}$, Lucio CosCo $^{8}$, Carmelo Laganà ${ }^{9}$, Angela Oliva ${ }^{9}$, Giuseppe Foti ${ }^{10}$, Maria Teresa Fiorillo ${ }^{11}$, \\ Giuseppa Lo Bocchiaro ${ }^{11}$, Pasquale Surace ${ }^{11}$, Anna Rita Ciccaglione ${ }^{12}$, Massimo Ciccozzi ${ }^{12}$, Francesco Cesario ${ }^{13}$, \\ Carlo Torti $^{14,15}$, Alfredo Focà ${ }^{{ }^{*}}$
}

From Third Workshop of the HCV Study Group in the Calabria Region

Catanzaro, Italy. 04 October 2013

\begin{abstract}
The epidemiological profile of HCV infection is evolving in Europe, as well as in Italy. We have previously showed genotype distributions and their dynamics in 2,153 HCV RNA positive patients living in Calabria, Southern Italy, over 11 years. In this study, we extend and update this information by evaluating a hospital-based cohort of 945 HCV RNA positive patients attending five hospitals in the Calabria Region from January 2011 to August 2013. We assessed rates of HCV genotypes according to age and gender and the dynamics of HCV genotype distribution over the 3-year period studied. Data showed that genotype $1 \mathrm{~b}$ is the most prevalent, followed by subtypes $2 \mathrm{a} / 2 \mathrm{c}$ and genotype 3. Genotype 4 exhibited an increase between 2011 and 2013. Also, we found a significant decrease in the median age of subjects infected with HCV genotype 3 and 4 during the period studied. Since HCV genotypes are important in epidemiology, pathogenesis and response to antiviral therapy, a continuous epidemiological surveillance is needed.
\end{abstract}

\section{Introduction}

Hepatitis C is a viral infection (HCV) of the liver and is one of the major causes of chronic liver diseases including complications such as cirrhosis and liver cancer [1]. The increases of cirrhosis and hepatocellular carcinoma (HCC) over time in HCV infected individuals are of particular concern [2]. So, the burden of HCV for patient health, society and health-care systems is substantial.

About 150 million people worldwide suffer from chronic HCV infection [3]. In Europe, an estimated 8 million people (1.3\%) are infected by HCV [4], but a heterogeneous pattern of prevalence has been reported. Indeed, while intermediate-to-high prevalence rates were

\footnotetext{
* Correspondence: alfredofoca@gmail.com

'Institute of Microbiology, Department of Health Sciences, "Magna Graecia" University, Catanzaro, Italy

Full list of author information is available at the end of the article
}

reported in Eastern and Southern Europe, Western and Northern Europe reported low prevalence rates $(\leq 1.0 \%)$. This emphasizes the importance of HCV infection, particularly in these parts of the world [5]. Also, the distribution of HCV genotypes shows a great heterogeneity, reflecting the differences in epidemiology, including modes of transmission and ethnic variability in different countries. Globally, genotype 1, especially type $1 \mathrm{~b}$ virus, causes approximately $90.0 \%$ of infections, while types 2,3 and 4 are less represented [6]. HCV genotypes 1 and 2 are universally distributed, whereas HCV genotypes 4, 5, 6 and 7 are confined to more specific geographical areas [7].

It has to be recognized, however, that surveillance systems for $\mathrm{HCV}$ are prone to underestimation due to the generally asymptomatic nature of acute infections, the marginalization of at risk populations or simply a lack of informative campaigns and testing for HCV. So, not 
only is data on the incidence of HCV infection limited, but data on its prevalence and subtype distribution is also incomplete [8].

In this paper, we report the contents of the presentation given at the third Workshop of the Regional Study Group on HCV in the Calabria Region (Southern Italy). In this presentation we reviewed prevalence and genotype distribution of $\mathrm{HCV}$ in Italy. Also, data from the Calabria Region were reviewed with a focus on special populations (migrants and intravenous drug users, IVDUs). Original and unpublished data updating previous estimates are presented from a hospital-based cohort of 945 HCV RNA positive patients attending five Hospitals in the Calabria region (January 2011 to August 2013).

\section{Current knowledge and limitations on general HCV epidemiology in Italy}

In November 2012, during World Hepatitis Day, the Italian Ministry of Health confirmed that prevalence of HCV seropositivity was higher in Southern and Insular areas (about $8.0 \%$ ) than in Central and Northern regions (about 2.0\%). However, the reports on which this statement were based are outdated or were obtained in limited areas [9-13]. Also, an active surveillance program for symptomatic acute hepatitis cases reported a rate of $0.2 / 100,000$ inhabitants in 2010. Although this is likely to be underestimated because it is well known that $\mathrm{HCV}$ infection is rarely symptomatic during its acute phase [14].

Risk factors for HCV infection in Italy have been traditionally related to nosocomial and healthcare related sources. Intravenous drug use, beauty treatment, hospitalization, surgical intervention, dental therapy and having more than two sexual partners were in decreasing order the most frequently reported risk factors [15]. However, the epidemiology of HCV infection has undergone substantial changes over the past two decades, with a progressive decrease in incidence and a shift in risk factors [16]. In particular, the most recent decrease in incidence rates could be due to changes in injecting behavior among IVDUs and information campaigns on HIV/AIDS. It has yet to be seen whether a reduction of information campaigns on HIV/AIDS will contribute to further resurgence of HCV in IVDU and/or in people with risky sexual behaviors.

Migration into Italy is a recent and growing phenomenon. It will influence prevalence of infections but data are still very limited. Indeed, in Italy, relatively high prevalences of HCV infection was detected by Eurostat 2008 in migrants coming from the following States: Albania 9.5\%, Romania 4.9\%, Morocco 1.1\% [17]. A study conducted by Surveillance Systems of ECDC (European Centre for Disease Prevention and Control) reported 26,678 cases of
HCV infection between 2007 and 2010; this corresponds to a rate of 6.93 per 100,000 population [18].

The Travel and Migration Medical Centre in Lamezia Terme (Catanzaro area, Italy) set up a screening program in migrants and refugees from North Africa (so called North Africa Emergency Program) in the Calabria Region. Herein we present major evidence from this program. Between July 2011 and June 2012, 1,278 immigrants arrived in the Calabria Region. Of the 1,050 adults and 228 children included, the top three countries of origin were: Somalia (20.0\%), Nigeria (18.0\%), and Ghana (10.0\%). Among these individuals, 767 consented to be screened and 32 (4.2\%) had chronic HCV infection (2 immigrants were HCV-HIV co-infected and 3 were $\mathrm{HCV}-\mathrm{HBV}$ co-infected). Age distribution of the HCV infected people was: $6.2 \%$ under 15 years, $75.0 \%$ between 16 and 30 years, $15.6 \%$ between 31 and 45 years, and 3.2\% above 45 years. More data and continuing surveillance are needed in the incoming migrants to understand whether and how persistence of $\mathrm{HCV}$ infected migrants and secondary transmission of $\mathrm{HCV}$ in the host population could modify current trends of the epidemics, prevalence of $\mathrm{HCV}$ subtypes and their prevalence distribution.

\section{Prevalence and distribution of HCV genotypes}

The overall prevalence of HCV RNA positive subjects in Italy is about $3.0 \%$ and more than $50.0 \%$ of these are older than 65 years [19]. These patients were the platform for HCV genotyping studies, but even these data are spotted and restricted to limited populations.

Amongst Italian IVDUs, Sereno et al. [20] reported that the $3 \mathrm{a} \mathrm{HCV}$ subtype was the most prevalent (41.3\%), followed by subtypes $1 \mathrm{a}(23.1 \%)$ and $1 \mathrm{~b}(20.6 \%)$. However, significant changes in the relative prevalence of genotypes have occurred since 1965: genotype 3 infections decreased from 48/116 (41.4\%) in 1965-1985 to $22 / 84(26.2 \%)$ in 1986-2006. Prevalence of genotype 4 was significantly higher in patients infected after 1985 compared to patients infected before this year.

Petruzziello et al. [21] assessed variations in the distribution of hepatitis $\mathrm{C}$ virus ( $\mathrm{HCV}$ ) genotypes in the metropolitan area of Naples, Italy. The authors observed that subtype $1 \mathrm{~b}(48.3 \%)$ and genotype $2(31.7 \%)$ were prevalent in older patients, whereas genotypes $3 \mathrm{a}$ and $1 \mathrm{a}$ were observed more frequently in the younger population. Genotype 1b was particularly common in females. Moreover, by comparing data observed from 2009 to 2011 with data related to a sample of $176 \mathrm{HCV}$ RNA positive patients collected from 2006 to 2008, a cohort effect emerged, with increasing prevalence of genotype $1 \mathrm{~b}$ among the elderly.

In the Calabria Region, we conducted an 11-year surveillance on HCV genotypes. During the 2001-2011 period, 
subtype $1 \mathrm{~b}$ was found to be the most prevalent (49.2\%) followed by subtype 2a/2c (22.4\%). Genotype 3 was the third most frequent $(7.4 \%)$, whereas genotype 4 showed a rate of $6.2 \%$. Interestingly, the prevalence of genotype 4 has increased in recent years, while median age of patients with HCV-4 appeared to decrease in 2006-2011 compared to $1997-2001$ and 2001- 2005 periods [22,23].

\section{Update on HCV genotypes in the Calabria region}

To better define epidemiology of HCV genotypes in the Calabria Region, here we report an analysis in the most recent years, following the same methodology of the previous studies, and including further geographical areas that were not previously considered. The update of our epidemiological analysis includes $945 \mathrm{HCV}$ RNA positive patients attending five hospitals from January 2011 to August 2013. Samples from 547 patients living in the Catanzaro area and attending University "Magna Grecia" Hospital, "Pugliese-Ciaccio" Hospital, and "Giovanni Paolo II" Hospital were collected. We also report a sample of 398 patients living in Reggio Calabria area and attending "Bianchi Melacrino Morelli" Hospital and "Polo Sanitario Nord Azienda Sanitaria Provinciale 5". The study was approved by "Magna Graecia" University Ethical Committee of Catanzaro, in compliance with Declaration of Helsinki. For this retrospective, nonpharmacological study, informed consent has not been provided by patients since it is not deemed to be necessary by Italian legislation.

HCV RNA from serum samples was extracted by Cobas AmpliPrep and detected by Cobas TaqMan HCV test (Roche Diagnostics, Milan, Italy). Versant HCV Genotype 2.0 Assay (Siemens, Healthcare Diagnostic Inc., Tarrytown, NY, USA) was performed according to the manufacturer's instructions. All patients were born in Italy, $550(58.2 \%)$ of them were male and 395 (41.8\%) were female.

Distribution of HCV genotypes in the $945 \mathrm{HCV}$ RNA positive patients attending clinical centers in Calabria Region stratified by gender is shown in Table 1. Subtype $1 \mathrm{~b}$ was the most prevalent (37.5\%) followed by subtype $2 \mathrm{a} /$ 2c (22.4\%). As previously observed [23] HCV 1b was not gender related. By contrast, from January 2011 to August 2013, subtype $2 \mathrm{a} / 2 \mathrm{c}$ was found mainly in female patients ( $45.7 \%$ male versus $54.3 \%$ female, $\mathrm{P}<0.05$ by $\chi^{2}$ test). Genotype 3 was the third most frequent $(11.8 \%)$ and was significantly more common in male patients $(83.9 \%$ male versus $16.1 \%$ female, $\mathrm{P}<0.05$ by $\chi^{2}$ test). Genotype 4 showed a rate of $7.5 \%$, with male versus female difference (67.2\% versus $32.8 \%, P=0.0712$ by $\chi^{2}$ test). Such significance index would suggest a statistical trend in this test. Therefore, here found a further increase of genotype 4 (Table 1) with respect to the previous studied period $2001-2011$ (6.2 \%) [23].

The overall dynamics of HCV genotypes in the 945 HCV RNA positive patients in the five healthcare facilities is reported in Figure 1. Subtype 1b decreased from 2011 (40.1\%) to 2012 (38.9\%) and to 2013 (31.2\%), while subtype $2 \mathrm{a} / 2 \mathrm{c}$ and genotype 3 did not vary significantly over time. Genotype 4 increased showing a peak of $10.1 \%$ during 2013. Statistical analysis of HCV patient age, stratified by genotypes, showed a significant decrease in median age of genotype 3 and genotype $4 \mathrm{HCV}$ infected subjects $(\mathrm{P}<$ 0.01 ANOVA plus Tukey test) (Figure 2). Data reported in this study confirm and statistically support previous observations [23,24].

Unfortunately, we could not extrapolate any association between specific HCV genotypes and risk factors for $\mathrm{HCV}$ acquisition due to the lack of data. With this objective in mind, we intend to implement our collaboration through

Table 1 HCV genotypes/subtypes distribution and gender of 945 patients from January 2011 to August 2013 in Calabria region.

\begin{tabular}{|c|c|c|c|c|c|c|c|}
\hline \multirow[t]{2}{*}{ HCV genotypes/subtypes } & \multirow[t]{2}{*}{ No. of isolates } & \multirow[t]{2}{*}{ Percentage (\%) } & \multicolumn{4}{|c|}{ Gender } & \multirow[t]{2}{*}{$P$ value } \\
\hline & & & Male & $(\%)$ & Female & $(\%)$ & \\
\hline 1 & 76 & 8.0 & 43 & 56.5 & 33 & 43.5 & NS \\
\hline $1 \mathrm{~b}$ & 354 & 37.5 & 191 & 53.9 & 163 & 46.1 & NS \\
\hline $1 \mathrm{a}$ & 73 & 7.7 & 47 & 64.4 & 26 & 35.6 & NS \\
\hline $1 a / 1 b$ & 5 & 0.5 & 4 & 80.0 & 1 & 20.0 & NS \\
\hline 2 & 42 & 4.5 & 26 & 61.9 & 16 & 38.1 & NS \\
\hline $2 a / 2 c$ & 212 & 22.4 & 97 & 45.7 & 115 & 54.3 & 0.0005 \\
\hline 3 & 112 & 11.8 & 94 & 83.9 & 18 & 16.1 & 0.0052 \\
\hline 4 & 70 & 7.5 & 47 & 67.2 & 23 & 32.8 & NS \\
\hline 5 & 1 & 0.1 & 1 & 100.0 & - & - & - \\
\hline Total & 945 & - & 550 & 58.2 & 395 & 41.8 & - \\
\hline
\end{tabular}

NS $=$ not significant $(P>0.05)$. 


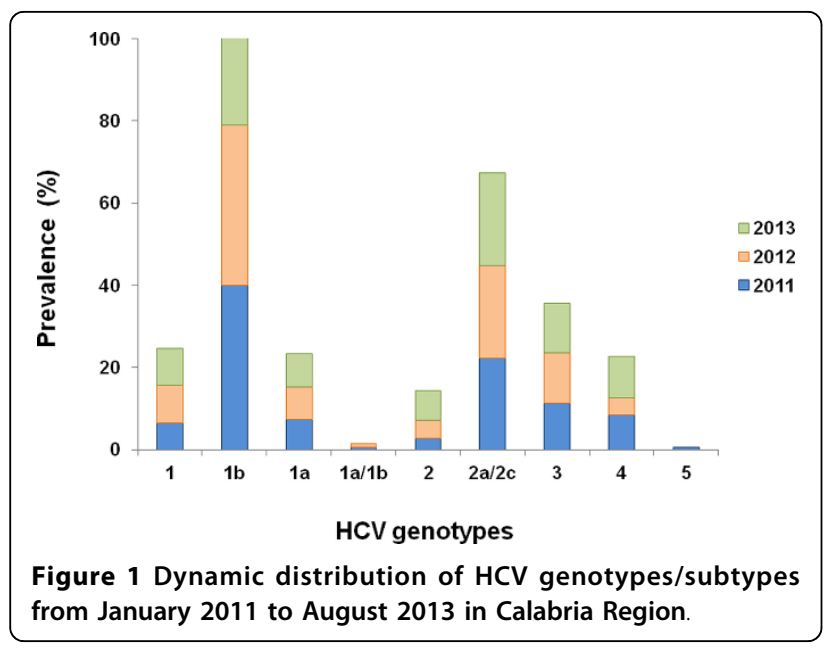

the SINERGIE network [25]. In the meantime, spotted observations have been collected. For example, Infectious Diseases Unit and Microbiology and Virology Unit of General Hospital (Lamezia Terme, Italy) seek to determine prevalence and distribution of HCV genotypes in Calabrian IVDUs. Fifty-six patients with chronic hepatitis $\mathrm{C}$ were examined between 2011 and 2013. This cohort was composed by 44 males $(78.6 \%)$ and 12 females $(21.4 \%)$ of whom 15 individuals (26.7\%) were co-infected with HIV. HCV 3a and 1a appeared to be the most frequent genotypes (1:3 each), confirming observations in different settings $[20,21]$.

\section{Conclusion}

From our review, we conclude that epidemiological studies were performed on a limited number of patients, who are not representative of the global Italian population. So, national surveillance programs are necessary. Moreover, further data on HCV prevalence and genotype distribution in migrant populations are urgently needed. In the Calabria Region, subtype $1 \mathrm{~b}, 2 \mathrm{a} / 2 \mathrm{c}$ and genotype 3 showed different associations with age and gender. HCV types $1 \mathrm{~b}$

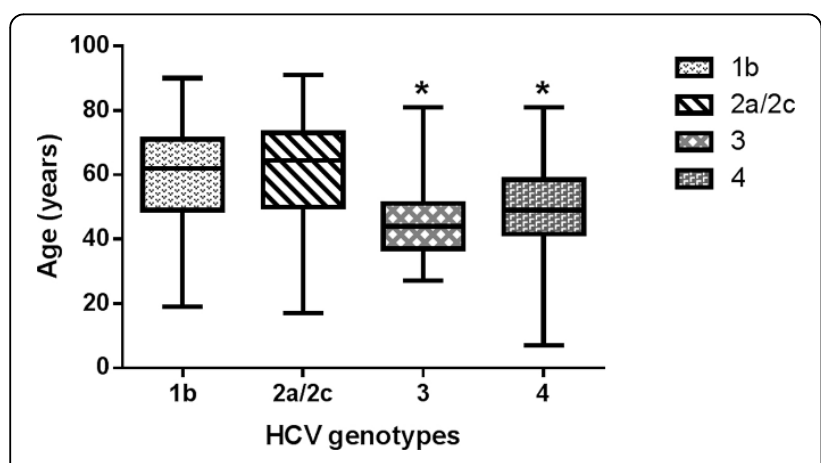

Figure 2 Box plot of genotypes 1b, 2a/2c, 3 and 4 distribution by HCV patients age in the January 2011-August 2013 period. ${ }^{*} \mathrm{P}<0.01$ versus genotypes $1 \mathrm{~b}$ and $2 \mathrm{a} / 2 \mathrm{c}$ (ANOVA plus Tukey test). and $2 \mathrm{a} / 2 \mathrm{c}$ were equally distributed among patients over and below 65 years. By contrast, genotype 4 and genotype 3 were more frequent in patients of younger age. Our updated estimations confirm a raise in genotype 4, in particular in the Catanzaro area. Lastly, surveillance performed in the North Africa Emergency Program revealed a chronic HCV infection in about $4.0 \%$ of individuals. This surveillance should continue both in autochthonous and migrant populations.

\section{List of abbreviations used}

HCV: Hepatitis C Virus; HCC : Hepatocellular Carcinoma; AIDS : Acquired Immune Deficiency Syndrome; IVDUs : Intravenous Drug Users.

\section{Competing interests}

The authors declare that they have no competing interests.

\section{Authors' contributions}

NM collected data, contributed to data analysis and to manuscript writing; $M C L$ performed design research and wrote the manuscript; GSB, EZ carried out HCV genotyping and collected data; $A Q, A G L, G B, G M$ contributed to data analysis; LS, GB, LS, VDM, FG collected clinical data; RAL, W, SN carried out HCV genotyping; AB, VC, MC, GG collected clinical data; RM, PM carried out HCV genotyping; LC, CL collected clinical data; AO carried out HCV genotyping, GF collected clinical data; MTF, GLB, PS carried out HCV genotyping; $A R C, M C$ contributed to manuscript writing; FC collected clinical data; CT contributed to data collection and manuscript revision; AF contributed to design research and wrote the manuscript.

\section{Acknowledgements}

SINERGIE Study Group is composed by the authors of the present article and by the following people: Maurizio Zazzi (Institute of Microbiology, University of Siena, Siena); Ludovico Abenavoli, Valentina Peta (Department of Health Sciences, University "Magna Graecia", Catanzaro); Francesco Trapasso (Unit of Medical Genetics, University "Magna Graecia", Catanzaro); Domenico Corigliano (Unit of Infectious Diseases, Ospedale "G. Jazzolino", Vibo Valentia); Alessio Strazzulla, Maria Concetta Postorino, Preziosa Scordo, Chiara Costa, Vincenzo Pisani (Unit of Infectious Diseases, University "Magna Graecia", Catanzaro); Cristina Giraldi (Unit of Microbiology and Virology, "Annunziata" Hospital, Cosenza); Nicola Serrao (Unit of Infectious Diseases, ASP Crotone, Crotone); Massimo Puoti (Department of Infectious Diseases, "Niguarda-Cà Granda" Hospital, Milan); Tiziana Larussa (Department of Health Sciences, University "Magna Graecia", Catanzaro); Maria Gabriella Lepore (Microbiology and Virology Unit, AO "Pugliese-Ciaccio", Catanzaro); Francesco Castelli, Serena Zaltron, Angiola Spinetti, Paola Nasta, Luciano Biasi (Infectious Diseases Department, University and Spedali Civili of Brescia, Brescia); Massimo De Siena, Sebastiano Di Salvo, Tiziana Gravina (Unit of Hepatology, "Mater Domini" General Hospital, Catanzaro); Alessandra Lo Presti, Gianguglielmo Zehender (National Institutes of Health, ISS, Rome).

\section{Declarations}

The publication of this supplement was partly supported by an unrestricted grant provided by Roche. The articles were independently prepared by the authors with no input from Roche. Roche were not involved in selecting the articles for the supplement.

This article has been published as part of BMC Infectious Diseases Volume 14 Supplement 5, 2014: Proceedings of the Third Workshop of the HCV Study Group in the Calabria Region: Results from the South Italian Network for Rational Guidelines and International Epidemiology (SINERGIE) Project. The full contents of the supplement are available online at http://www. biomedcentral.com/bmcinfectdis/supplements/14/S5.

\section{Authors' details}

${ }^{1}$ Institute of Microbiology, Department of Health Sciences, "Magna Graecia" University, Catanzaro, Italy. ${ }^{2}$ Clinic of Infectious Diseases and Hepatology, General Hospital, Lamezia Terme, Italy. ${ }^{3}$ Unit of Infectious Diseases, General Hospital, Lamezia Terme, Italy. ${ }^{4}$ Unit of Hepatology, University Teaching 
Hospital, Pisa, Italy. ${ }^{5}$ Unit of Hepatology, Hospital "Mater Domini", Catanzaro, Italy. ${ }^{6}$ Microbiology and Virology Unit, General Hospital, Lamezia Terme, Italy. ${ }^{7}$ Microbiology and Virology Unit, "Pugliese-Ciaccio" Hospital, Catanzaro, Italy. ¿Unit of Infectious Diseases, "Pugliese-Ciaccio" Hospital, Catanzaro, Italy. "Microbiology and Virology Unit, "Bianchi Melacrino Morelli" Hospital, Reggio Calabria, Italy. ${ }^{10}$ Unit of Infectious Diseases, "Bianchi-Melacrino-Morelli" Hospital, Reggio Calabria, Italy. ${ }^{11}$ Microbiology and Virology Unit, Polo Sanitario Nord ASP 5, Reggio Calabria, Italy. ${ }^{12}$ National Institutes of Health, ISS, Rome, Italy. ${ }^{13}$ Unit of Infectious Diseases, "Annunziata" Hospital, Cosenza, Italy. ${ }^{14}$ Unit of Infectious Diseases, Department of Medical and Surgical Sciences, "Magna Graecia" University, Catanzaro, Italy. ${ }^{15}$ University Unit of Infectious Diseases, University of Brescia, School of Medicine, Brescia, Italy.

Published: 5 September 2014

\section{References}

1. Shepard CW, Finelli L, Alter MJ: Global epidemiology of hepatitis C virus infection. Lancet Infect Dis 2005, 5:558-567.

2. Grebely J, Dore GJ: What is killing people with hepatitis C virus infection? Semin Liver Dis 2011, 31:331-339.

3. 2012 World Health Organization (WHO): Hepatitis C 2011 [http://www.who. int/mediacentre/factsheets/fs164/en/], [accessed July 2013]

4. Mühlberger N, Schwarzer R, Lettmeier B, Sroczynski G, Zeuzem S, Siebert U: $\mathrm{HCV}$-related burden of disease in Europe: a systematic assessment of incidence, prevalence, morbidity, and mortality. BMC Public Health 2009, 9:34.

5. Hatzakis A, Wait S, Bruix J, Buti M, Carballo M, Cavaleri M, Colombo M, Delarocque-Astagneau E, Dusheiko G, Esmat G, Esteban R, Goldberg D, Gore C, Lok AS, Manns M, Marcellin P, Papatheodoridis G, Peterle A, Prati D, Piorkowsky N, Rizzetto M, Roudot-Thoraval F, Soriano V, Thomas HC, Thursz M, Valla D, van Damme P, Veldhuijzen IK, Wedemeyer H, Wiessing L, Zanetti $A R$, Janssen $H L$ : The state of hepatitis $B$ and $C$ in Europe: report from the hepatitis B and C summit conference*. J Viral Hepat 2011, 18(Suppl 1):1-16.

6. Ciccozzi M, Ciccaglione AR, Lo Presti A, Yalcinkaya T, Taskan ZP, Equestre M, Costantino A, Bruni R, Ebranati E, Salemi M, Gray R, Rezza G, Galli M, Zehender G: Reconstruction of the evolutionary dynamics of the hepatitis C virus 1b epidemic in Turkey. Infect Genet Evol 2011, 11(5):863-868.

7. Simmonds P: The origin of hepatitis C virus. Curr Top Microbiol Immunol 2013, 369:1-15.

8. Seeff LB: Natural history of chronic hepatitis C. Hepatology 2002, 36(5 Suppl 1):S35-46.

9. Campello C, Poli A, Dal MG, Besozzi-Valentini F: Seroprevalence, viremia and genotype distribution of hepatitis C virus: a community-based population study in northern Italy. Infection 2002, 30(1):7-12.

10. Raffaele A, Valenti M, lovenitti M, Matani A, Bruno ML, Altobelli E, D'Alessandro A, Barnabei R, Leonardis B, Taglieri G: High prevalence of $\mathrm{HCV}$ infection among the general population in a rural area of central Italy. Eur J Epidemiol 2001, 17(1):41-46.

11. Coppola RC, Masia G, Pradat P, Trepò C, Carboni G, Argiolas F, Rizzetto : Impact of hepatitis $C$ virus infection on healthy subjects on an Italian island. J Viral Hepat 2000, 7(2):130-137.

12. Maio G, d'Argenio P, Stroffolini T, Bozza A, Sacco L, Tosti ME, Intorcia M, Fossi E, d'Alessio G, Kondili LA, Rapicetta M, Mele A: Hepatitis C virus infection and alanine transaminase levels in the general population: a survey in a southern Italian town. J Hepatol 2000, 33(1):116-120.

13. Ansaldi F, Bruzzone B, Salmaso S, Rota MC, Durando P, Gasparini R, Icardi G: Different seroprevalence and molecular epidemiology patterns of hepatitis C virus infection in Italy. J Med Virol 2005, 76(3):327-332.

14. 2012 World Health Organization (WHO): World Hepatitis Day 2012. [http:// www.who.int/crr/disease/hepatitis/world_hepatitis_day/en/index.html], [accessed July 2013].

15. Zuccaro O, Tosti ME, Mele A, Spada E, SElEVA Collaborative Group: Epidemiology of acute viral hepatitis in Italy: results of the surveillance through SEIEVA. Annual Report Rome; 2012.

16. Mariano A, Scalia Tomba G, Tosti ME, Spada E, Mele A: Estimating the incidence, prevalence and clinical burden of hepatitis $C$ over time in Italy:. Scand J Infect Dis 2009, 41:689-699.

17. European Commission, Eurostat. [http://epp.eurostat.ec.europa.eu].
18. Surveillance Report 2012: Annual epidemiological report Reporting on 2010 surveillance data and 2011 epidemic intelligence data [http://www.ecdc. europa.eu].

19. Mariano A, Tomba G, Tosti ME, Spada E, Mele A: Future burden of hepatitis $C$ virus infection: the case of Italy. In: 41st Annual Meeting of the European Association for the Study of the Liver (EASL). Annual Meeting Vienna; 2006.

20. Sereno $S$, Perinelli $P$, Laghi V: Changes in the prevalence of hepatitis $C$ virus genotype among Italian injection drug users - Relation to period of injection started. J Clin Virol 2009, 45:354-357.

21. Petruzziello A, Coppola N, Diodato AM, lervolino V, Azzaro R, Di Costanzo G, Di Macchia CA, Di Meo T, Loquercio G, Pasquale G, Cacciapuoti C: Age and gender distribution of hepatitis $C$ virus genotypes in the metropolitan area of Naples. Intervirology 2013, 56(3):206-212.

22. Matera G, Lamberti A, Quirino A, Focà D, Giancotti A, Barreca GS, Guadagnino V, Liberto MC: Changes in the prevalence of hepatitis $C$ virus (HCV) genotype 4 in Calabria, Southern Italy. Diagn Microbiol Infect Dis 2002, 42:169-173.

23. Marascio N, Matera G, Quirino A, Giancotti A, Barreca GS, Lamberti AG, Caroleo B, Liberto MC, Focà A: Eleven-year distribution pattern of hepatitis C virus in southern Italy. J Pathog 2012, 2012:631095, doi: 10.1155/2012/631095.

24. Liberto MC, Marascio N, Zicca E, Matera G: Epidemiological features and specificities of HCV infection: a hospital-based cohort study in a university medical center of Calabria region. BMC Infect Dis 2012, 12(Suppl 2):S4, doi: 10.1186/1471-2334-12-S2-S4.

25. Torti C, Zazzi M, Abenavoli L, Trapasso F, Cesario F, Corigliano D, Cosco L, Costa C, Curia RL, De Rosa M, Foti G, Giraldi C, Leone R, Liberto MC, Lucchino D, Marascio N, Masciari R, Matera G, Pisani V, Serrao N, Surace L, Zicca E, Castelli F, Ciccozzi M, Puoti M, Focà A, SINERGIE Study Group: Future research and collaboration: the "SINERGIE" project on HCV (South Italian Network for Rational Guidelines and International Epidemiology). BMC Infect Dis 2012, 12(Suppl 2):S9, doi:10.1186/1471-2334-12-S2-S9.

doi:10.1186/1471-2334-14-S5-S2

Cite this article as: Marascio et al:: Update on epidemiology of HCV in Italy: focus on the Calabria Region. BMC Infectious Diseases 2014 14(Suppl 5):S2.

\section{Submit your next manuscript to BioMed Central and take full advantage of:}

- Convenient online submission

- Thorough peer review

- No space constraints or color figure charges

- Immediate publication on acceptance

- Inclusion in PubMed, CAS, Scopus and Google Scholar

- Research which is freely available for redistribution

Submit your manuscript at www.biomedcentral.com/submit
Ciomed Central 